control for all confounding differences between study cohorts, their findings suggest that AAW may be an ideal choice for the elderly patient population or those with a reduced life expectancy, especially those in whom prolonged cardiopulmonary bypass times and/or hypothermic arrest might not be tolerated. Because proximal arch redilation may occur, yearly rates appear to be insidious, and periodic postoperative surveillance may be warranted.

\section{References}

1. Kim H-H, Lee S, Lee SH, Youn Y-N, Yoo K-J, Joo H-C. The long-term fate of ascending aorta aneurysm after wrapping versus replacement. J Thorac Cardiovasc Surg. 2022;164:463-74.e4.

2. Gonzalez-Santos JM, Arnaiz-Garcia ME. Wrapping of the ascending aorta revisited: is there any role left for conservative treatment of ascending aortic aneurysm? J Thorac Dis. 2017;9(Suppl 6):S488-97.

3. Neri E, Massetti M, Tanganelli P, Capannini G, Carone E, Tripodi A, et al. Is it only a mechanical matter? Histologic modifications of the aorta underlying external banding. J Thorac Cardiovasc Surg. 1999;118:1116-8.

4. Doyle M, Peeceeyan S, Bonar F, Horton M. Rarefaction of the aorta under Dacron wrap: a rare complication. Interact Cardiovasc Thorac Surg. 2014;19:341-3.

\title{
Commentary: Wrap one's aorta around
}

\author{
Vicente Orozco-Sevilla, MD, ${ }^{\mathrm{a}, \mathrm{b}, \mathrm{c}}$ and \\ Tomas A. Salerno, MD $^{\mathrm{d}}$
}

Wrapping techniques, with or without aortoplasty, ${ }^{1-3}$ have been used as a less-invasive surgical alternative for the treatment of moderately dilated aortas during other cardiac surgery procedures (ie, those that are not primarily focused on aortic repair). Additionally, there are subsets of patients with aortic disease, such as those with advanced age or those with multiple comorbidities, that face a greatly enhanced risk of operative death during proximal aortic repairs (eg, of the ascending aorta and transverse arch) that center on aortic replacement. ${ }^{4}$ Aside from the aortic wrapping technique's technical simplicity, enthusiasm for its use is low due to the lack of long-term results, especially in comparison to alternate approaches

From the ${ }^{\mathrm{a}}$ Division of Cardiothoracic Surgery, Michael E. DeBakey Department of Surgery, Baylor College of Medicine, Houston, Tex; ${ }^{\mathrm{b}}$ Section of Adult Cardiac Surgery, Department of Cardiovascular Surgery, Texas Heart Institute; Houston, Tex;

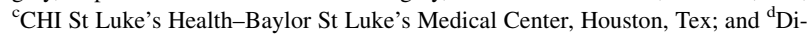
vision of Cardiothoracic Surgery, Miller School of Medicine, University of Miami and Jackson Memorial Hospital, Miami, Fla.

Disclosures: The authors reported no conflicts of interest.

The Journal policy requires editors and reviewers to disclose conflicts of interest and to decline handling or reviewing manuscripts for which they may have a conflict of interest. The editors and reviewers of this article have no conflicts of interest.

Received for publication March 29, 2021; revisions received March 29, 2021; accepted for publication March 29, 2021; available ahead of print April 2, 2021.

Address for reprints: Tomas A. Salerno, MD, Division of Cardiothoracic Surgery, Miller School of Medicine, University of Miami, 1611 NW 12th Ave, Miami, FL 33136 (E-mail: tsalerno@med.miami.edu).

J Thorac Cardiovasc Surg 2022;164:476-7

$0022-5223 / \$ 36.00$

Copyright (c) 2021 by The American Association for Thoracic Surgery

https://doi.org/10.1016/j.jtcvs.2021.03.099

such as aorta replacement. Presumed complications of aortic wrapping include migration, erosion, ulceration, and atrophy of the aortic wall caused by possible biomechanical, structural, and histologic changes associated with the wrapping. ${ }^{5}$

Kim and colleagues ${ }^{6}$ provide us with an update of their experience with the management and long-term prognosis of 4 other aortic regions (ie, annulus, sinus, ascending aorta, and proximal arch) when a moderately dilated ascending aorta during aortic valve surgery was wrapped or replaced. The authors reviewed 964 patients undergoing aortic valve surgery between 1995 and 2018; they excluded patients with congenital anomalies or aortic dissections and patients who had concomitant aortic root or aortic arch surgery or concomitant mitral valve or 
tricuspid valve surgery. From 204 remaining patients, a propensity score matching study was performed comparing a total of 140 patients who were split into 2 groups: those who received aortic wrapping $(\mathrm{n}=70)$ and those who received aortic replacement $(\mathrm{n}=70)$. Although there was no in-hospital death, the replacement group's intensive care unit stay was longer. The diameter of the tubular ascending aorta or root components did not vary between the groups in terms of stability. During the excellent long-term follow-up (3.9-11.2 years), the authors reported that men with a preoperative ascending diameter $>47 \mathrm{~mm}$ and hypertension had significantly higher adverse aortic events, such as dilation of the proximal aortic arch and late reoperations for dissection or rupture, indicating that close postoperative surveillance monitoring is needed. In 2013, these same authors suggested a more conservative approach, in which aortic valve replacement alone (in patients with moderately dilated ascending aortas) achieved similar clinical outcomes to either aortic wrapping or aortic replacement. ${ }^{7}$ In the 2013 study, despite a shorter follow-up period (24.5-68 months), the authors concluded that in patients with moderately dilated aortas there were liberal management choices that could be tailored to individual patient conditions. For example, in regard to patient-specific surgical risk and life expectancy, wrapping of the aorta was helpful in stabilization of the aorta.

Regarding the present study, ${ }^{6}$ the authors should be commended for their considerable efforts to provide us with data that will allow us to understand this controversial topic. External wrapping is a basic technique that, when performed correctly, stabilizes the ascending aorta, the sinuses of the aortic root, and the annulus of the aortic valve. So, what causes the proximal arch to dilate? The distribution of wall stress at the junction of the ascending aorta and proximal arch is among the arguments used in an aortic wrapping model. ${ }^{8}$ In our own clinical practice, we selectively reinforce the distal anastomosis by wrapping it with a strip of polyethylene terephthalate. Additionally, in patients with "thin" nondilated aortas or in patients with bicuspid valve aortopathy, we occasionally reinforce the native aortic tissue between the innominate and left common carotid arteries in this fashion. It is unclear whether the type of arch, whether it be Gothic or Romanesque, ${ }^{9}$ or if the length of the aorta ${ }^{10}$ will play a role in wrapping failure. We believe this entire field is evolving. Improved technology, such as personalized external aortic root support, ${ }^{11}$ has already set the tone for future advancements in this field. With an eye to the future, it will not be long before endovascular technology will be used for internal wrapping rather than external wrapping of the aorta. We hope that surgeons will keep an open mind and get involved when these advancements occur, and in the meantime, aortic wrapping should be in the armamentarium of every surgeon.

\section{References}

1. Robicsek F, Cook JW, Reames MK Sr, Skipper ER. Size reduction ascending aortoplasty: is it dead or alive? J Thorac Cardiovasc Surg. 2004; 128:562-70

2. Gill M, Dunning J. Is reduction aortoplasty (with or without external wrap) an acceptable alternative to replacement of the dilated ascending aorta? Interact Cardiovasc Thorac Surg. 2009;9:693-7.

3. Cohen O, Odim J, De la Zerda D, Ukatu C, Vyas R, Vyas N, et al. Long-term experience of girdling the ascending aorta with Dacron mesh as definitive treatment for aneurysmal dilation. Ann Thorac Surg. 2007;83:S780-4.

4. Estrera AL, Miller CC III, Huynh TT, Porat EE, Safi HJ. Replacement of the ascending and transverse aortic arch: determinants of long-term survival. Ann Thorac Surg. 2002;74:1058-64.

5. González-Santos JM, Arnáiz-García ME. Wrapping of the ascending aorta revisited-is there any role left for conservative treatment of ascending aortic aneurysm? J Thorac Dis. 2017;9:S488-97.

6. Kim H-H, Lee S, Lee SH, Youn Y-N, Yoo K-J, Joo H-C. The long-term fate of ascending aorta aneurysm after wrapping versus replacement. J Thorac Cardiovasc Surg. 2022;164:463-74.e4.

7. Lee SH, Kim JB, Kim DH, Jung SH, Choo SJ, Chung CH, et al. Management of dilated ascending aorta during aortic valve replacement: valve replacement alone versus aorta wrapping versus aorta replacement. J Thorac Cardiovasc Surg. 2013;146:802-9.

8. Plonek T, Rylski B, Dumanski A, Siedlaczek P, Kustrzycki W. Biomechanical analysis of wrapping of the moderately dilated ascending aorta. J Cardiothorac Surg. 2015;10:106.

9. Ou P, Celermajer DS, Raisky O, Jolivet O, Buyens F, Herment A, et al. Angular (Gothic) aortic arch leads to enhanced systolic wave reflection, central aortic stiffness, and increased left ventricular mass late after aortic coarctation repair: evaluation with magnetic resonance flow mapping. J Thorac Cardiovasc Surg. 2008; 135:62-8.

10. Wu J, Zafar MA, Li Y, Saeyeldin A, Huang Y, Zhao R, et al. Ascending aortic length and risk of aortic adverse events: the neglected dimension. J Am Coll Cardiol. 2019;74:1883-94

11. Treasure T, Petrou M, Rosendahl U, Austin C, Rega F, Pirk J, et al. Personalized external aortic root support: a review of the current status. Eur J Cardiothorac Surg. 2016;50:400-4. 